\title{
Bicentenary of the birth of Thomas Young, M.D., F.R.S.
}

\author{
GERALD FONDA \\ Short Hills, New Jersey, U.S.A.
}

Thomas Young was a scientist, physician, physicist, mathematician, linguist, philosopher, $\frac{O}{0}$. and decipherer of Egyptian hieroglyphics. He was born at Milverton, England, on June 0 I3, I 773, the eldest of ten children. The family was strictly Quaker and their meeting house was but a few feet to the rear of Young's birthplace (Fig. I), where his father conducted a business as cloth merchant and banker. The street was formerly known as $\mathscr{O}^{\circ}$ Quaker Street and is now renamed North Street.

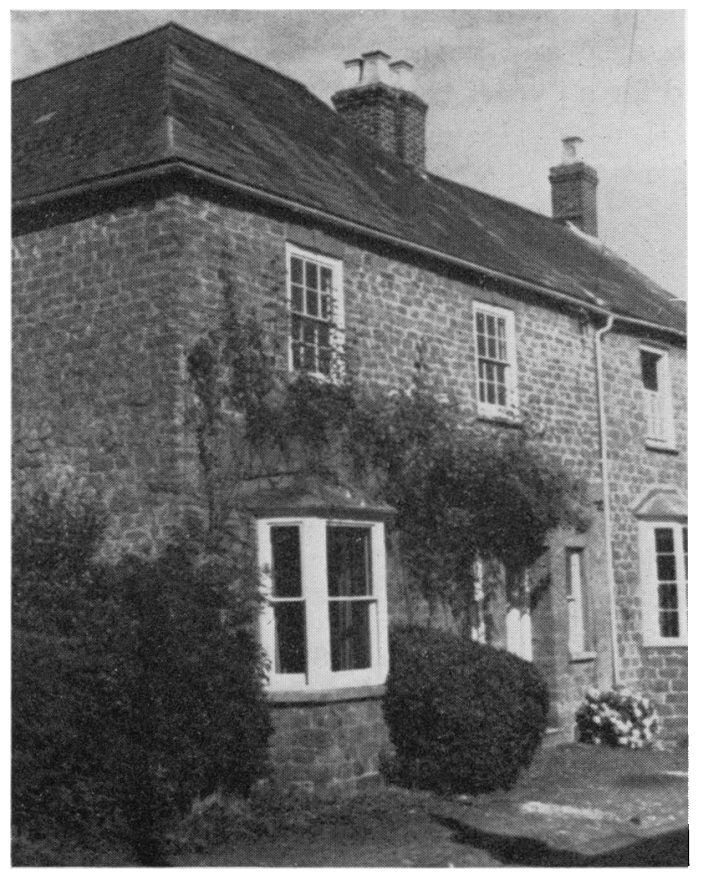

F I G. I Birthplace of Thomas Young, North Street, $\stackrel{\circ}{\stackrel{\circ}{े}}$ Milverton, England. The house was known as $\overrightarrow{\vec{F}}$ Quaker's Lodge

Young's remarkable precocity was demonstrated by his ability to read fluently at the age of 2 years and to recite Oliver Goldsmith's The Deserted Village when he was 6 years old. N్ At 14 he had a ready knowledge of Latin, Greek, Italian, French, Hebrew, Chaldee, 0 Persian, Syrian, and Arabic. Young, one of the founding fathers of physical, geometric, $\bullet$ and physiological optics, may have been the most versatile genius of all time.

For the most part, Young was self-educated. His formal education consisted of 9 years $?$ at three different boarding schools, some tutelage, and experience with an assistant teacher in lathe-turning and telescope making. The record testifies that he was a stable, diligent $\stackrel{\mathbb{D}}{\mathbb{D}}$ 
student and by the age of 19 had obtained an exceptionally thorough education in sciences, 을 mathematics, and languages. His remarkable mastery of Latin and Greek greatly impressed his great-uncle, Richard Brocklesby, who was an eminent London physician and a classical scholar in his own right. Among Brocklesby's circle were Edmund Burke, $\stackrel{\because}{\vec{\Rightarrow}}$ Samuel Johnson, and many aristocrats. With his genius Young made a startling impres- $\stackrel{\overrightarrow{0}}{\stackrel{9}{+}}$ sion on this group when he was introduced to them by his great-uncle.

At the encouragement of his father and Dr. Brocklesby, Young declined an offer to $\frac{\bar{D}}{\bar{N}}$ become private secretary to the Duke of Richmond in order to train for the medical $\frac{\vec{D}}{\mathrm{O}}$ profession. He entered the Hunterian School of Anatomy (William Hunter) in London when he was ig. In the course of his studies, a dissection of the eye of an ox stimulated $\vec{\circ}$ his interest in accommodation, and in the same year Young presented his paper, "The Mechanism of the Accommodation of the Eye," before the Royal Society of London. The following year he became a fellow of the Royal Society. At Edinburgh Young continued $\frac{}{0}$. his medical education and also at Göttingen, Germany, where he received his diploma 0 in 1796 . In the meantime, he abandoned Quaker customs while at Edinburgh where he: took dancing lessons and began to attend the theatre.

The new regulations of the College of Physicians of London dictated that the privilege of their fellowship was granted only to those who had studied medicine for 2 years at $\stackrel{\circ}{工}$ Oxford or Cambridge. Young, therefore, attended and graduated with a diploma from $\vec{z}$ Emmanuel College, Cambridge, in 1799 and began his medical practice at 48 Welbeck Street, London, where he remained for 23 years (Fig. 2).

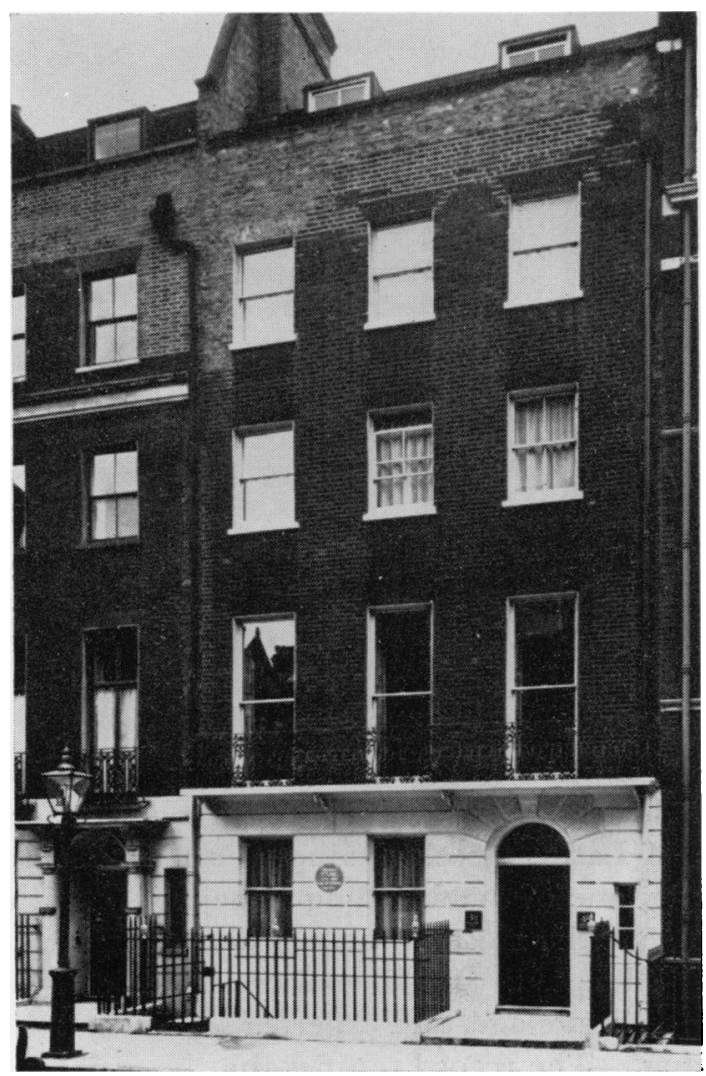

FIG. 248 Welbeck Street, where Thomas roung $\stackrel{\circ}{3}$ practised medicine from 1800 to 1823 (An agency for the blind is now located here) 
From 1801 to 1803 Young was Professor of Physics at the Royal Institution of Great Britain. In 1802 , he gave a series of fifty lectures, which was extended in 1803 to sixty lectures, dealing with physics, hydrodynamics, and mechanics. They were published in 1807 with some revisions, in two large volumes. The lectures were original and profound, but were not to be discovered and appreciated until a generation later. Young's original contributions on colour vision, the theory of interference, the optical constants of the eye, and the extent of the visual field were included in this series. Young was not very successful as a lecturer at the Royal Institution. His intricate and sophisticated material was far beyond the comprehension of his audience, which consisted largely of the famous and the fashionable of both sexes. Furthermore, his presentation was generally dry and colourless. Yet the preparation of fifty thorough and wide-ranging lectures within the space of less than a year remains an astounding achievement. Young resigned from the Royal Institution in 1803 , explaining that his duties there interfered with his practice of medicine. Many of his scientific contributions were published anonymously so that the public would not learn that he was devoting so much of his time, talent, and effort to other pursuits.

In 1808 , Young received his M.D. degree from Cambridge and in 1809 was elected to fellowship of the Royal College of Physicians. He was appointed to the important position of physician at Saint George's Hospital in I8I I. Young conducted a respectable, though not a notably great, practice in London from November to June and during the remainder of the year he worked at Worthing, on the south coast, where fashionable society gathered. After moving to 9 Park Square in Regent's Park in 1826 , Young continued his work at Saint George's, but discontinued his private practice. It is well to keep in mind that the practice of medicine in the early i 9 th century consisted of bleeding, purging, and sweating, all of which may well have hastened the demise of the patient in many cases. The success of a doctor depended largely upon a good bedside manner, which Young certainly seems to have lacked. He was gentle and polite, though not warm, and probably not sufficiently comforting. It is quite likely that he subscribed less to the conventional forms of treatment because he recognized their lack of rationale.

From 1809 to 18 I $_{5}$, Young lectured and wrote extensively, covering all aspects of medicine. His lectures were delivered to the staff at Saint George's and the Middlesex hospital. Although his preparation was intensive and his knowledge profound, he would present, in an hour, much more than his audience could absorb. His manner lacked warmth and earnestness, and he seemed to pass over the points of greatest interest to the students. The current observation among the students was that "Doctor Young was a great philosopher, but a bad physician".

Young's two principal texts were Introduction to Medical Literature, 586 pages in length (of which there were two editions), and Practical, Historical Treatise on Consumptive Diseases, 49 I pages in length. In addition to these, he wrote five articles for the Quarterly Review and several others for the Imperial Review. Rarely did Young make an original contribution to general medicine. His medical publications were organized presentations reviewing all the available literature on the subject. Young preferred research to practice, and the publications were intended to extend his practice.

Except for his investigation of accommodation of the eye, Young's contributions to optics were made in the period of 2 years, while he was Professor of Physics at the Royal Institution; these may be listed as follows:

(1) Mechanism of accommodation in the lens;

(2) Exposition of phenomenon of interference of light waves; 
(3) Calculation of wave lengths of seven colours of spectrum;

(4) Origination of trichromatic theory of colour vision;

(5) First measurement of astigmatism;

(6) First measurement of the field of vision and size of the blind spot;

(7) First geometrical construction of a refracted ray, due to an incident ray falling on a spheric surface;

(8) Equations of field of geometric optics (still used by optical designers);

(9) First statement of the concept of a continuous spectrum passing from ultraviolet to infrar with production of heat;

(10) First estimation of the diameter of a molecule.

(I) Young's earliest scientific paper (I 793) dealt with the accommodation of the ey $\vec{\omega}$ The ability to see near was believed by different men to be explained by an increase length of the eyeball, increased curvature of the cornea, or increased thickness of the lew of the eye. By a series of experiments, Young proved that the increased focus of the exo was caused by the lens becoming thicker and thereby optically stronger. The mechanis $\vec{m}$ for the increased thickness of the lens was not defined because the existence of the ciliarig

muscles was not known.
(2) It was Young who first presented and explained the general law of the interference of light which served as the foundation for the wave theory of light.

(3) Using the phenomenon of interference, he calculated the wave lengths of seven colou家 of the spectrum.

(4) Originating the trichromatic theory of colour vision, Young stated that there vere three principal colours-red, green, and blue-from which all others could be prodused According to this theory, each principal colour was represented by an individual ngeg fibre. Helmholtz rediscovered and modified the theory 50 years later and it has since bee known as the Young-Helmholtz Theory of Colour Vision. Young seems to have bee⿳亠丷厂巾 the first to suggest the use of the colour top for scientific colour mixture.

(5) Young was also the first to measure astigmatism. This he did with an optometer ho made, modelled after Porterfield's. The optometer Young used is shown in Fig. 3.

By using the optometer to measure the far point of his eye, he was the first to recognize and measure astigmatism.

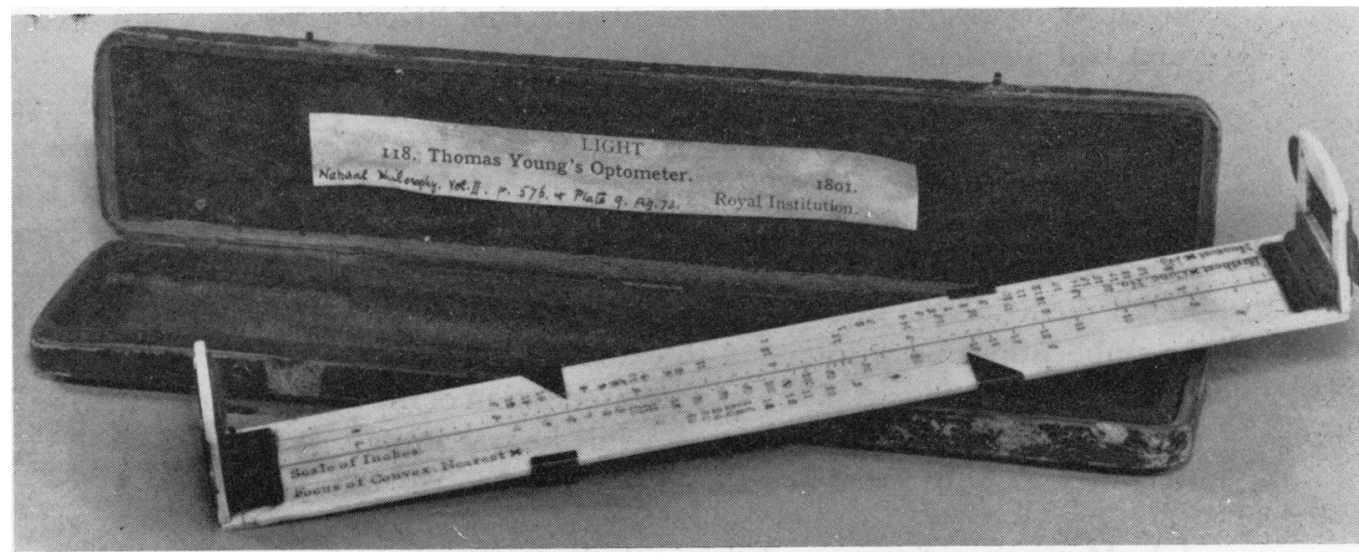

FIG. 3 Optometer devised and used by Young to measure his own astigmatism. 
My eye, in a state of relaxation, collects to a focus, on the retina, those rays which diverge vertically from an object at the distance of ten inches from the cornea, and the rays which diverge horizontally from an object at seven inches distance. For, if I hold the plane of the optometer vertically, the images of the line appear to cross at ten inches; if horizontally, at seven. I have never experienced any inconvenience from this imperfection, nor did I ever discover it 'til I made these experiments; and I believe I can examine minute objects with as much accuracy as most of those whose eyes are differently formed.

Young's lens correction was $-4 \mathrm{D}$ sph. $-\mathrm{I} \cdot 75 \mathrm{D}$ cyl., axis $90^{\circ}$. He believed that astigmatism was caused by the tilting of the lens.

Young measured the anterior posterior diameter of his eyeball at $23 \mathrm{~mm}$. and the radius of his cornea at $7.87 \mathrm{~mm}$. These measurements are very close to those officially accepted.

There was no department of knowledge which was not at Young's command. He made a major contribution to the decipherment of the hieroglyphics of the Rosetta Stone. In addition to optics, his publications dealt with weights and measures, life assurance and

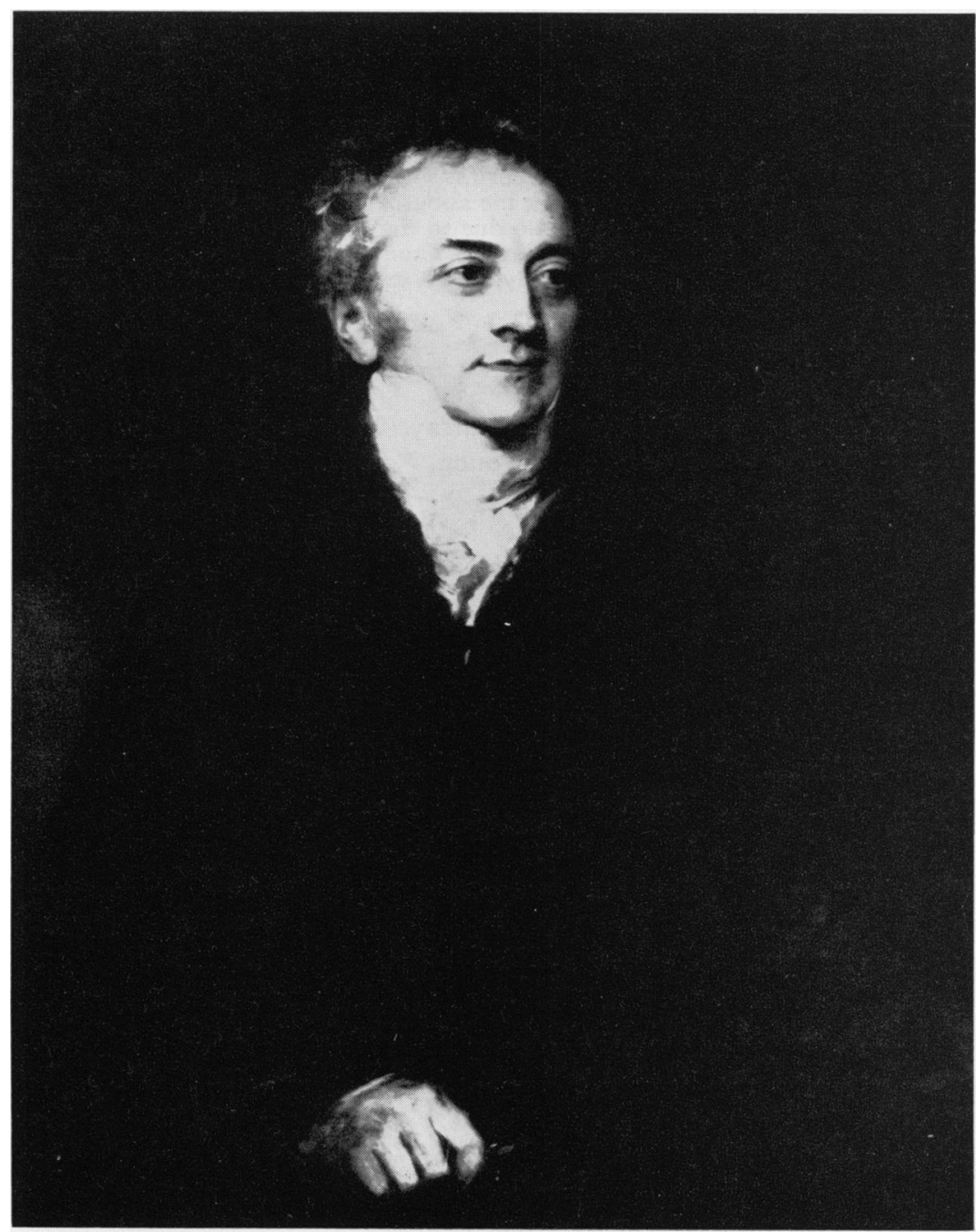

FIG. 4 Photograph of the originalportrait by Sir Thomas

Lawrence 
actuarial science, botany, sound, cohesion and resistance of fluids, theory of tides and waves, architecture, gravitation, construction of ships, density of the earth, astronomical measure. ments, principle of compound interest, and many others, in addition to which he published a nautical almanac. He also made calculations on the motion of a body projected from? the moon.

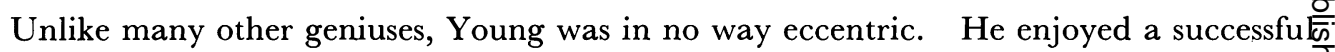
marriage and was regarded with esteem and affection by his wife and sisters-in-law. He⿻ played the flute with some ability and enjoyed dancing, singing, and attending concerts As a student at Göttingen he was better known as a horseman and gymnast than as a $\rightarrow$ Greek scholar. He died May I0, 1828 , at the age of 56 from an ossification of the aorta. His portrait by Sir Thomas Lawrence is shown in Fig. 4.

Young was not very successful as a practising physician, nor as a teacher of medicine, $\frac{0}{0}$. although he exerted every effort to assure success. This is not surprising when we recallif that the clinical thermometer, stethoscope, and sphygmomanometer were not yet available, and that Pasteur had not yet proved the germ basis of infection. Consequently, there wasio no really effective, rational treatment. Unfortunately for ophthalmology and for himself, $\mathrm{\omega}$ Young was born 200 years too soon. Today he would probably be a giant in the research of physical, geometric, and physiological optics, enjoying success as a scientific physician, with a more appreciative and knowledgeable audience.

I am indebted to Mr. Quentin Gurney, Norfolk, for assisting me to obtain a photograph of the painting of Thomas Young, and to Mr. E. C. Kirk for telling me about and showing me the location in Milverton mostD closely associated with him. My gratitude is also due to the staff of the Royal Institution library for thejir courtesy in allowing me to examine material relating to Thomas Young, and for permission to photografhce the optometer which he designed and used. Finally, I wish to thank Mrs. Granville-Jones for the opportunky of visiting where Thomas Young was born.

\section{Bibliography}

PEACOCK, G. (1855) "Life of Thomas Young". Murray, London. wood, A., and oldham, F. (1954) "Thomas Young, Natural Philosopher, 1 773-1829." University

Press, Cambridge. 